\title{
When a patient walks in with a knife in his back: A scene from the movies, a case report
}

\author{
Tuhin Shah ${ }^{1}$ and Arjana Shakya ${ }^{1}$ \\ ${ }^{1}$ Asia Pacific Medical College
}

April 28, 2020

\begin{abstract}
Stab wounds are commonly seen in the emergency room of community hospitals especially in developing countries. The uniqueness of the case to be reported here was that the patient walked in the ER retaining the inflicting weapon in the wound over his back.
\end{abstract}

\section{Key Clinical Message:}

It is important to remember and involve multidisciplinary departments whenever necessary in the management of the patients for the best possible result.

\section{INTRODUCTION:}

Violence has been central to the human civilization since the origin of the humans itself, and has been increasing everyday be it due to poverty, unemployment or simply to establish power. Here a case of a 28 year old male who was stabbed in the back with a home-made knife is described with preoperative and operative pictures.

\section{CASE DESCRIPTION:}

A 28 year male walked into the emergency room with an alleged history of a fight an hour back and was attacked with a weapon, a home-made knife, which was still lodged into the back of the patient in the midline with minimal bleed from the entry point. (Figure 1 ) He gave a positive history for alcohol consumption the same day with mild intoxication. He did have some abrasions and bruising to his upper torso and complained of pain and tenderness in the area of the lodged weapon with no active bleed.

In the emergency room ATLS guidelines were followed where the airway, breathing and circulation where intact and normal. The patient was comprehensible with a GCS of 15/15 and all neurological facilities intact. A secondary survey did not reveal any other significant injuries to the body. Initial plain X-Rays demonstrated a triangular opaque shadow at a depth of 5-7 cms into the body at the level of $8^{\text {th }}-9^{\text {th }}$ dorsal vertebrae close to the midline with no fracture. (Figure 2 ) Since the patient's neurological survey, the spinal cord and the vertebrae was intact and after discussion with the radiologist it was established that there was no injury to it. A USG scan was done to evaluate with no positive finding in the back region nor in the abdomen.

He was taken into the operation theatre and under general anesthesia, the patient was placed in prone position and the stab site was explored and the knife extracted. (Figure 3 ) The home-made knife was lodged $6 \mathrm{cms}$ deep into the body lodges in the muscles and next to the $8^{\text {th }}-9^{\text {th }}$ vertebrae. There was no injury to any vertebrae or to the major vascular structures and organs. (Figure 4 ) The knife seemed to have 
deflected off the spinous and transverse processes of the dorsal vertebrae, which to the luck of the patient saved any major and devastating injuries. The wound was closed in layers and the patient was shifted to the ward. The patient was discharged on $2^{\text {nd }}$ post-operative day and he is on regular follow-up for the last 5 months and is asymptomatic and healthy.

\section{DISCUSSION:}

Violence and bodily injury can result due to many factors and causes. We are in a world of

Stab wounds are most commonly homicidal, followed by suicidal and accidental. (1) Alcohol intoxication makes the clinical evaluation of such patients more difficult. (2) Literature shows the incidence of stabbing to be higher in young men, most to the thoracic spine (61\%) and least to the lumbar spine (7\%). (3)

Direct central back stabbings rarely produce serious injuries to the spinal cord and the retroperitoneal structures due to the presence of muscles and vertebras, with the spinous and transverse processes deflecting the blows laterally. There is a lot of debate regarding the management of stab wounds to the back and flank. Mainly as they can pose a special problem due to the difficulty in clinically evaluating the retroperitoneal organs with physical exam and FAST. In a clinically stable patient, non-operative management can be tried with the use of triple contrast CT scan as a tool to ensure no serious injury is present. (4)

Digital exploration of the wound under local anesthesia can be done for assessment of peritoneal breach but is not useful for evaluation of intra-abdominal injuries. The local wound exploration must be technically adequate, sufficient exposure of the wound is required to follow the tract of the stab. (5) Some trauma centers advocate mandatory laparotomy for all penetrating stab wounds to the abdomen. (6)

However, in case of intestinal eviscerations the treatment includes prompt resuscitation, exclusion of other injuries, with an early and careful laparotomy allowing uneventful recovery a possibility. Immediate laparotomy is necessary in patients with hemodynamic instability, presence of peritonitis, evisceration, or impalement injuries. (7) The policy of mandatory laparotomy leads to many negative laparotomies, up to $53 \%$. (8)

Mandatory laparotomy was considered the standard of care for abdominal stab wounds and gunshot wounds till the 1960s. The dictum of mandatory laparotomy for anterior abdomen wall stab wounds was challenged and a policy of "selective conservatism" was used, in which management was based primarily on clinical evaluation. (9) Also since there are significant consequences of unnecessary laparotomy in terms of morbidity, hospital stay, and costs and even mortality.

There were many tests aimed at determining whether the peritoneum had been entered, including sinography (10) and local wound exploration. (11)

\section{Author Contribution Statement:}

\section{Tuhin Shah:}

Conception and design

Acquisition, analysis and interpretation of data

\section{Arjana Shakya:}

Analysis and research

\section{REFERENCES:}

1. Nandy A. Mechanical Injuries. In: Principles of Forensic Medicine. 3rd ed. Kolkata: New Central Book Agency; 2010.

2. D.Demetriades, B. Rabinotiz. Indications for operation in abdominal stab wounds. Aprospective study of 651 patients. Ann. Surg.1987, 205: 129 - 30 .

3. Ritchie DA: Stab injury to the lumbar spine. British Journal of Hospital Medicine 1993, 49(8):574-5. 
4. Boyle EM Jr, Maier RV, Salazar JD, Kovacich JC, O'Keefe G, Mann FA, Wilson AJ, Copass MK, Jurkovich GJ: Diagnosis of injuries after stab wounds to the back and flank. Journal of Trauma-Injury Infection \& Critical Care 1997, 42(2):260-5.

5. Rosenthal RE, Smith J, Walls RN et al. Stab wounds to the abdomen: failure of blunt probing to predict peritoneal penetration. Ann Emerg Med 1987; 16:172-75.

6. Wilson H, Sherman RT. Civilian penetrating wounds of the abdomen, factors in mortality and differences from military wounds in 494 cases. Annals Surgery, 1961: 153: 639-644.

7. Shah T (2017). A Case Report of a Paediatric Intestinal Evisceration by Road Traffic Accident in Nepal. SAJ Case Rep 4: 305.

8. Forde KA, Ganepola GA. Is mandatory exploration for penetrating abdominal trauma extinct? The morbidity and mortality of negative exploration in a large municipal hospital. J Trauma. 1974 Sep;14(9):764766.

9. Shaftan GW (1960) Indications for operation in abdominal trauma. Am J Surg 1999:657-664.

10. Cornell WP, Ebert PA, Greenfield LJ et al (1965) A new non-operative technique for the diagnosis of penetrating injuries to the abdomen. J Trauma 7:307-314.

11. . Thompson JS, Moore EE, Van Duzer-Moore S et al (1980) The evolution of abdominal stab wound management. J Trauma 20:478-484 .

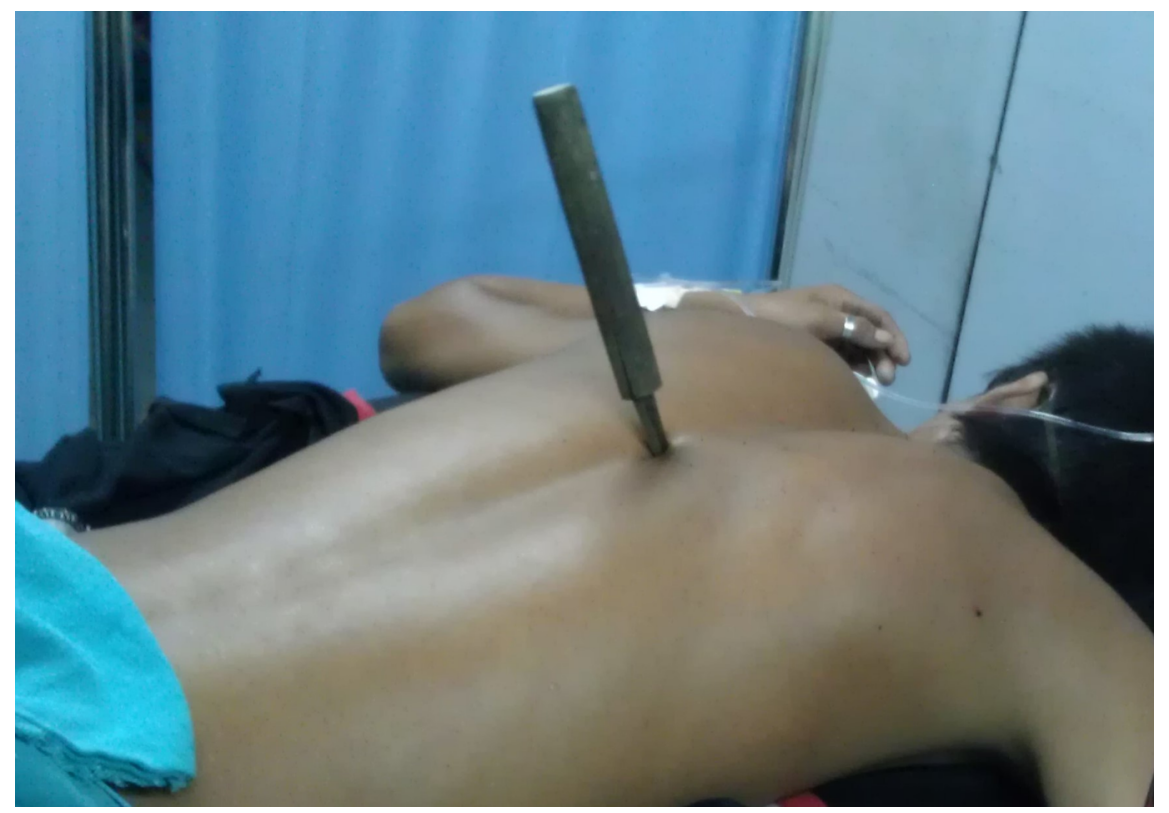



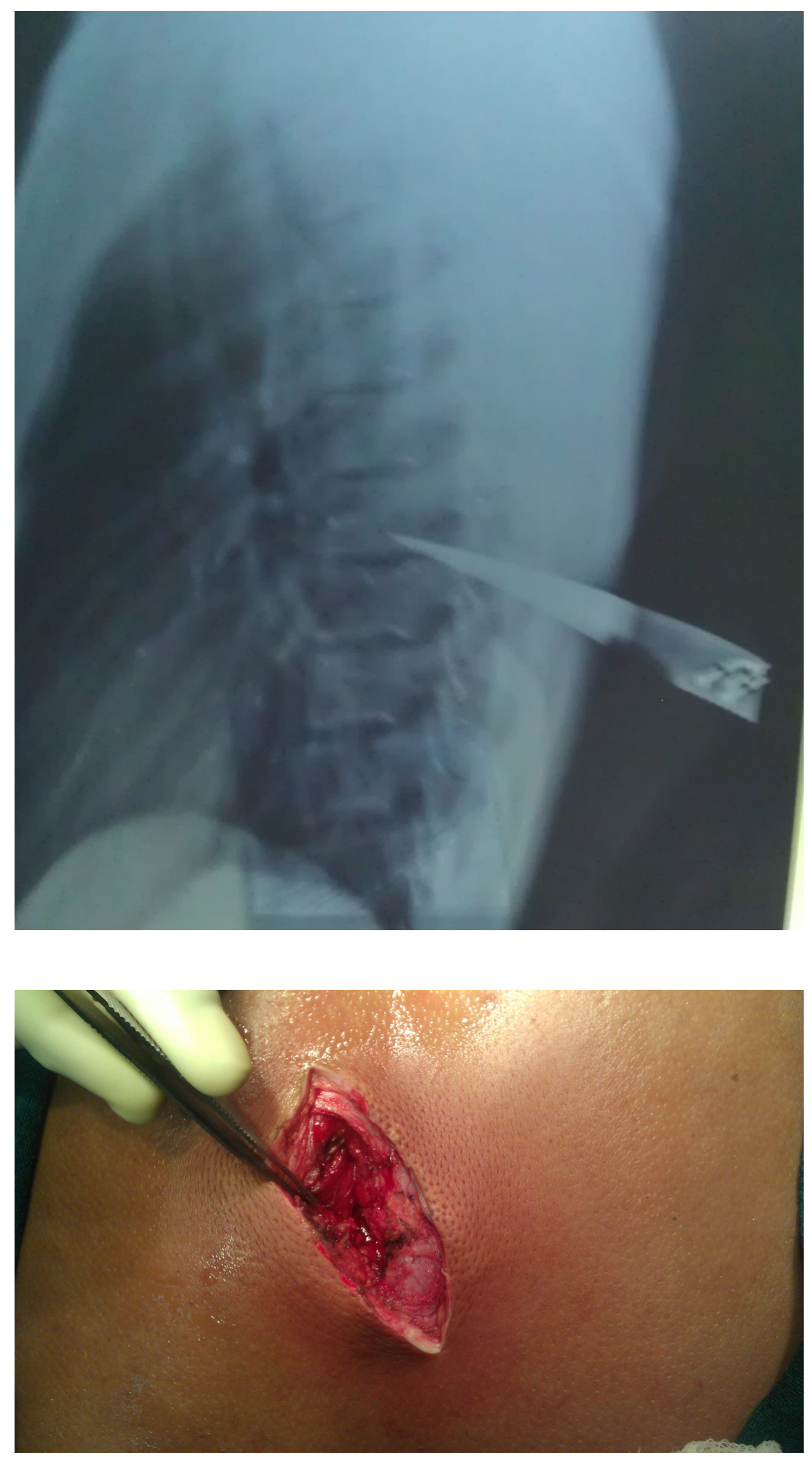


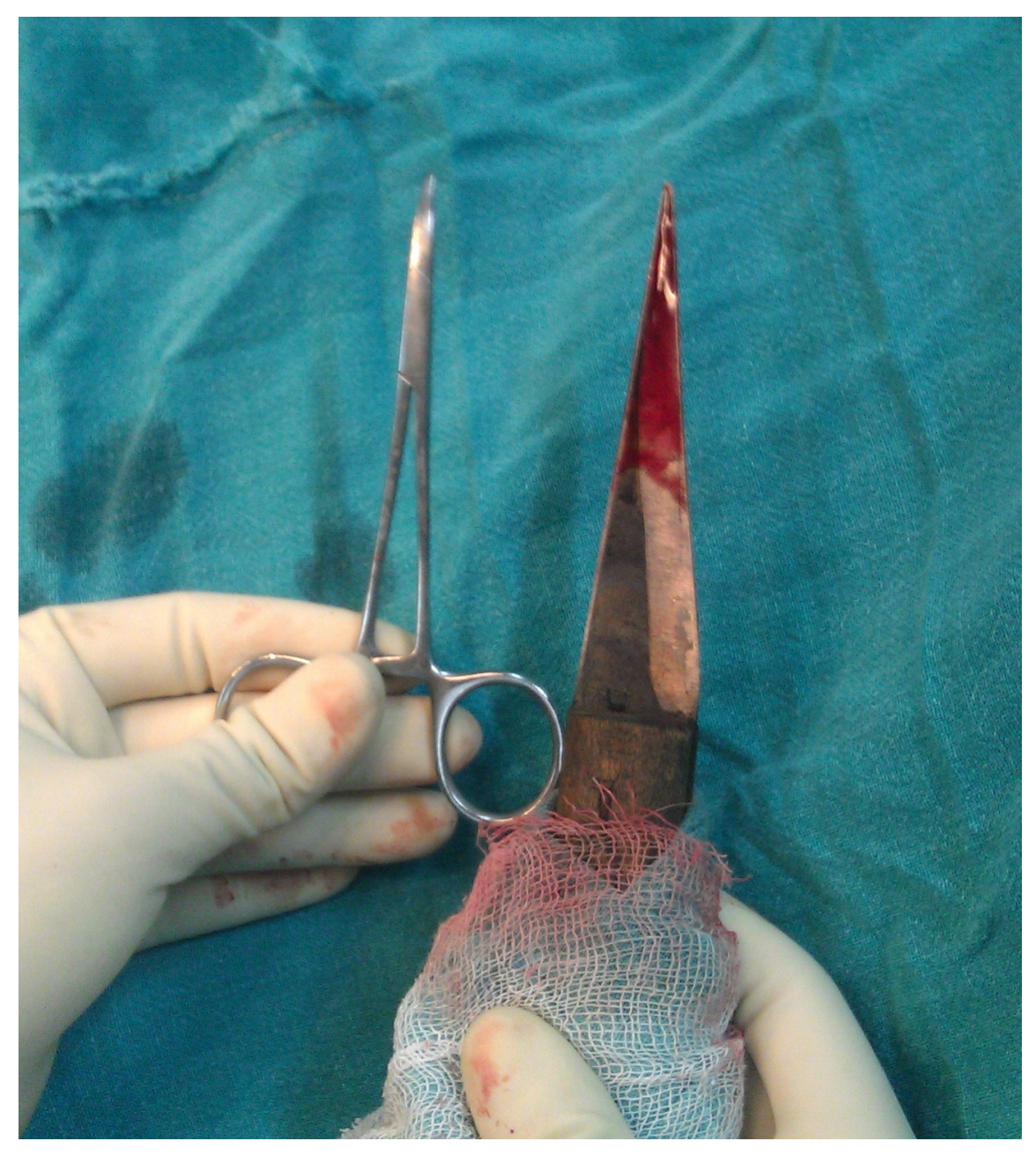

